
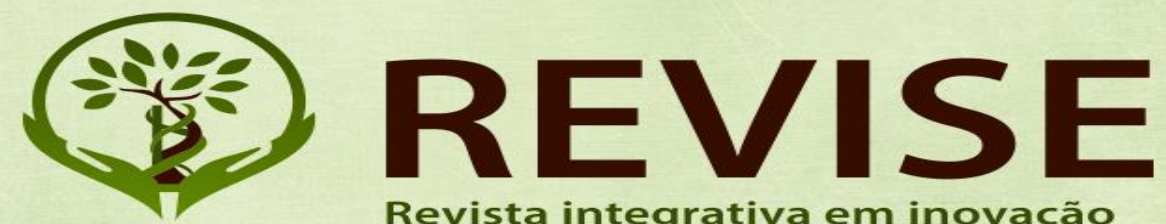

Revista integrativa em inovação tecnológica nas ciências da saúde

ISSN: 2179-6572
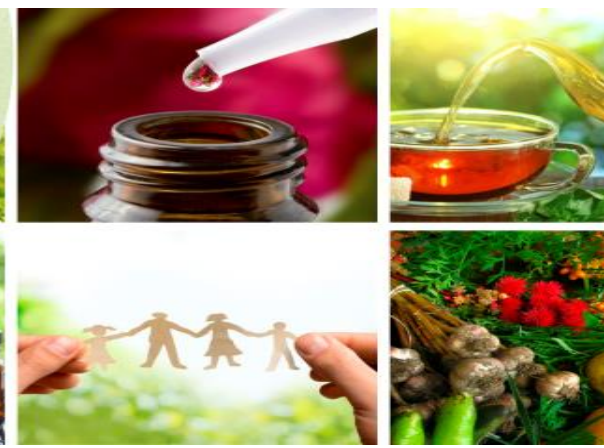

\title{
CONHECIMENTO POPULAR ACERCA DO USO DE PLANTAS MEDICINAIS EM CIDADES DO EXTREMO SUL DA BAHIA
}

\author{
Reinan do Carmo Souza \\ Fernanda Moreau de Almeida Soares \\ Gustavo Teixeira Pires \\ Lívia Santos Lima Lemos \\ Andrea Lizabeth Costa Gomes \\ $U F S B$
}

\begin{abstract}
Resumo
Apesar do avanço do conhecimento técnico científico quanto ao desenvolvimento dos fármacos industrializados e sintéticos, o uso das plantas medicinais como métodos alternativos ou complementares no tratamento de enfermidades continua sendo uma prática dentre as comunidades tradicionais transmitida através das gerações. Este estudo teve como objetivo realizar um levantamento etnobotânico das plantas utilizadas com finalidades terapêuticas e o conhecimento de moradores de cidades do extremo sul da Bahia. Para isso foi disponibilizado um questionário online nas redes sociais para recolhimento dos dados. Dentre os 85 respondentes, foram identificadas 72 espécies de plantas e suas respectivas utilizações terapêuticas. As partes das plantas mais utilizadas são a folha, o caule, a flor, a raiz e a casca na forma de infusos, macerados e/ou suco. As plantas mais utilizadas foram: erva cidreira, capim santo, boldo, camomila, erva doce, babosa e hortelã. As principais indicações terapêuticas foram: gripe, resfriado, problemas intestinais, estresse, ansiedade, dor de cabeça, inflamações e febre. O conhecimento popular e o uso das plantas medicinais permanecem amplamente preservadas pelas pessoas no extremo sul da Bahia.
\end{abstract}

Palavras-chave: Fitoterápicos; Extremo Sul Baiano; Uso caseiro; Plantas Medicinais. 

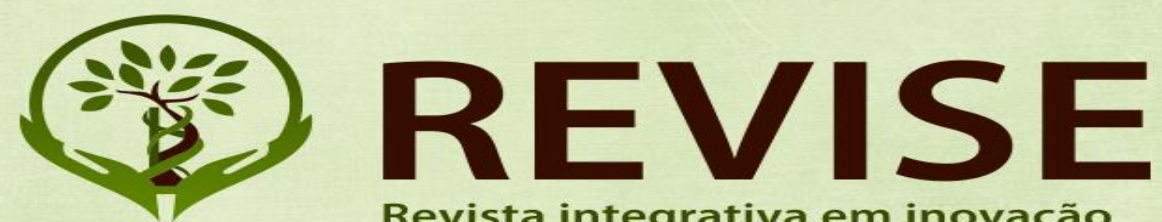

Revista integrativa em inovação tecnológica nas ciências da saúde

ISSN: $2179-6572$

\author{
POPULAR KNOWLEDGE ON THE USE OF MEDICINAL PLANTS \\ IN EXTREMELY SOUTHERN CITIES OF BAHIA
}

\begin{abstract}
Despite the advance of technical scientific knowledge regarding the development of industrialized and synthetic drugs, the use of medicinal plants as alternative or complementary methods in the treatment of diseases remains a practice among traditional communities transmitted through the generations. The objective of this study was to carry out an ethnobotanical survey of the plants used for therapeutic purposes and the knowledge of residents of cities in the extreme south of Bahia. For this purpose, an online questionnaire was made available on social networks to collect data. Among the 85 respondents, 72 species of plants and their respective therapeutic uses were identified. The parts of the plants most used are the leaf, the stem, the flower, the root and the bark in the form of infusions, macerated and / or juice of the same. The most used plants were lemon grass, holy grass, boldo, chamomile, sweet grass, slime and mint. The main therapeutic indications were flu, cold, intestinal problems, stress, anxiety, headache, inflammations and fever. Popular knowledge and the use of medicinal plants remain widely preserved by people in the extreme south of Bahia.

Keywords: Herbal medicines; Far South Bahia; Home use; Medicinal plants
\end{abstract}



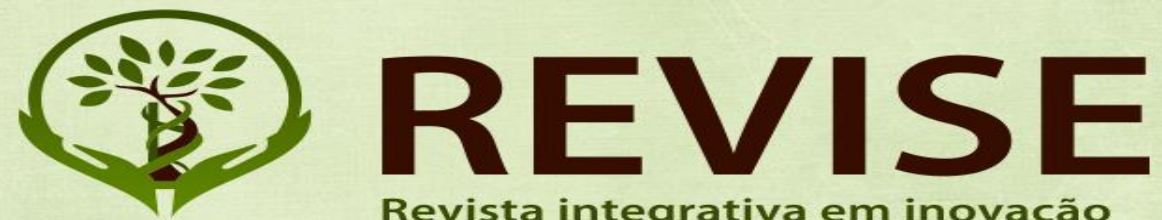

Revista integrativa em inovação tecnológica nas ciências da saúde

ISSN: 2179-6572

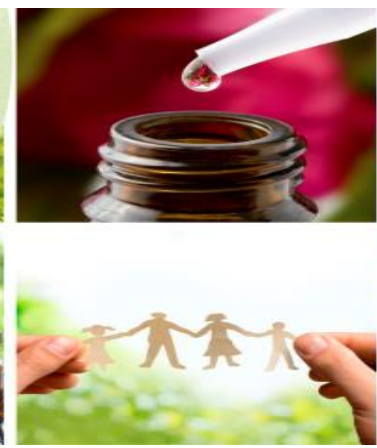

\section{INTRODUÇÃO}

A utilização de plantas medicinais para o tratamento de enfermidades é uma prática milenar cujo conhecimento das finalidades terapêuticas das plantas advém grande parte do conhecimento adquirido pelas comunidades tradicionais, transmitido através da oralidade e escritos ao longo das gerações. Apesar do avanço do conhecimento técnicocientífico para o desenvolvimento dos fármacos industrilizados e sintéticos, o uso das plantas medicinais como método alternativo ou complementar no tratamento de enfermidades continua sendo uma realidade. (Vasconcelos, Alcoforado, \& Lima, 2010). Ainda hoje, as plantas medicinais, para muitas comunidades representram a primeira opção para tratamentos de doenças, assim como ocorreu com gerações anteriores. De acordo com um estudo realizado na comunidade indígena de Ventarra Alta-RS, no qual 35 famílias foram entrevistadas e questionadas quanto ao tipo de tratamento que procuram quando adoencem, 74,28\% dos entrevistados afirmaram optar pelo uso de plantas medicinais. Mesmo tendo acesso aos medicamentos adquiridos em farmácias, a comunidade mantém o hábito de preparo de tratamentos caseiros à base de plantas coletadas principalmente em matas próximas à comunidade como controle de enfermidades. (Coan \& Matias, 2014). Para as pessoas que habitam a região que contempla a Mata Atlântica no Extremo Sul da Bahia, não é diferente, pois sempre fizeram uso medicinal das plantas deste bioma. Porém, com o crescimento dos medicamentos industrializados e a perda da cobertura original da Mata Atlântica - que levou a extinção de muitas plantas - esta prática se enfraqueceu e a prática do uso de muitas espécies está ameaçada (Pinto, Amorozo, \& Furlan, 2006).

Para Veiga Junior et al (2005), as plantas medicinais e a medicina tradicional também estão fortemente ligadas, não só pela semelhança de princípios, mas também pela utilização de plantas da flora nativa como base para o tratamento de várias doenças. Além disso, o conhecimento de populações tradicionais sobre plantas medicinais é um elemento amplamente

Plantas medicinais. Revista Revise, vol 3, no fluxo contínuo, p.46-60. 

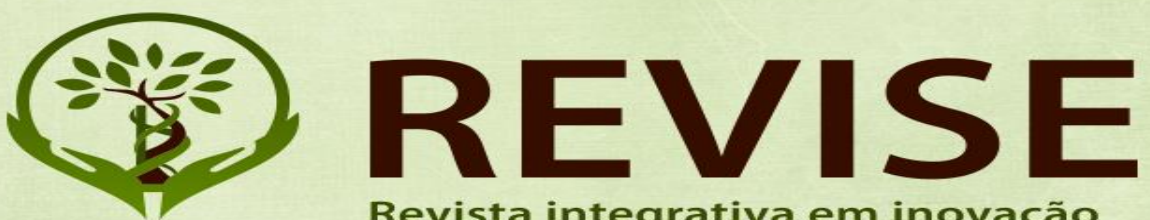

Revista integrativa em inovação tecnológica nas ciências da saúde

ISSN: 2179-6572
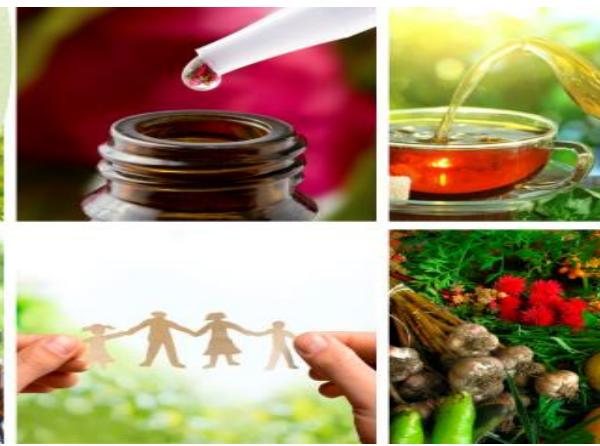

valorizado por pesquisadores que trabalham no desenvolvimento de novos fármacos para combater enfermidades (Sá, 2006). Segundo Badke et al (2011), as diversas mudanças políticas, sociais e econômicas, levaram as pessoas a reverem os modelos de cuidado propostos pela indústria farmacêutica. A promessa de cura das mais variadas doenças a partir dos fármacos, desencadeou a ocorrência de outras enfermidades, devido ao uso indiscriminado, levando a um crescimento considerável da utilização das plantas medicinais. Em 2006, foi aprovado o Programa Nacional de Plantas Medicinais e Fitoterápicos, que tem como um de seus objetivos "desenvolver instrumentos de fomento à pesquisa, desenvolvimento de tecnologias e inovações em plantas medicinais e fitoterápicos, nas diversas fases da cadeia produtiva" (Ministério da Saúde, 2009), assim o investimento em pesquisas neste campo vem aumentando gradativamente. Para isso, pode-se sugerir que o Extremo Sul da Bahia venha a ser um lugar de descobertas grandiosas, por ser uma região originalmente coberta pela mata atlântica. Ainda são poucas as informações, apesar de sua importância ecológica, a biodiversidade e várias espécies exclusivas da região (Moreira et al., 2002), que atualmente abriga 13 municípios. Embora os locais que ainda se encontram preservados com a vegetação original serem poucos, as pesquisas na área podem apresentar resultados positivos acerca do assunto. Diante da importância que as plantas medicinais têm para a região, o objetivo deste trabalho foi realizar um levantamento etnobotânico das plantas utilizadas com finalidades terapêuticas e do conhecimento de moradores das cidades localizadas no Extremo Sul da Bahia.

\section{MÉTODO}

Elaborou-se um questionário eletrônico quantiqualitativo semiestruturado com 11 perguntas, sendo 7 subjetivas e 4 objetivas, a partir da plataforma GoogleForms. Com a divulgação nas redes sociais via Facebook e WhatsApp, 85 pessoas responderam ao convite para participar do estudo. As perguntas do questionário possibilitaram traçar o perfil dos participantes com dados de idade, sexo e cidade onde residem. Foi também analisado se o indivíduo já utilizou alguma

Plantas medicinais. Revista Revise, vol 3, $n^{o}$ fluxo contínuo, p.46-60. 

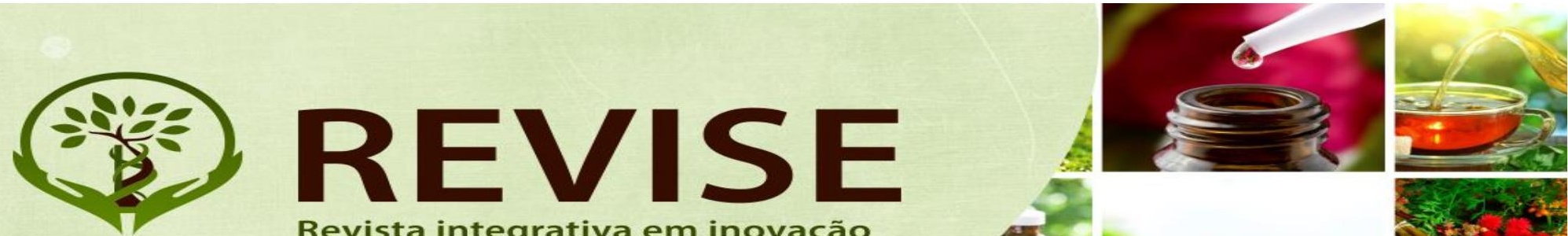

Revista integrativa em inovação tecnológica nas ciências da saúde

ISSN: $2179-6572$

planta com finalidade medicinal, os tipos e as partes das plantas usadas, o modo de preparo e se o tratamento adotado foi eficaz quanto a enfermidade alvo e/ou secundária cuja planta alega ter atividade terapêutica. Foi questionado também sobre a origem do conhecimento adquirido relativo aos benefícios das plantas utilizadas. Os critérios utilizados para compor a avaliação dos dados coletados foram a quantidade de vezes que a planta foi citada, sua efetividade e o meio que o entrevistado utilizou para se cientificar sobre as propriedades medicinais da(s) planta(s) citada(s). A partir do levantamento, foram quantificados o número de plantas citadas e suas indicações. Após o reconhecimento das plantas, as espécies foram identificadas por meio de uma pesquisa bibliográfica especializada. Os resultados apresentam dados como nome popular da planta, nomenclatura científica, quantidades de vezes que a espécie foi reportada, indicação terapêutica popular para cada espécie, informações de uso, forma de preparo e parte utilizada.

\section{RESULTADOS E DISCUSSÃO}

O perfil dos participantes obtido quanto ao sexo revelou uma maioria de indivíduos do sexo feminino $(69,4 \%)$ e 30,6\% do sexo masculino. Quanto a idade, 79\% tinham entre 15 a 40 anos, $15,5 \%$ tinham de 41 a 60 anos, e 3,5\% mais de 60 anos (Tabela 1). Das 85 respostas, 76 $(89,4 \%)$ fizeram o uso de plantas medicinais e $9(10,6 \%)$ nunca utilizaram.

Plantas medicinais. Revista Revise, vol 3, $n^{o}$ fluxo contínuo, p.46-60. 

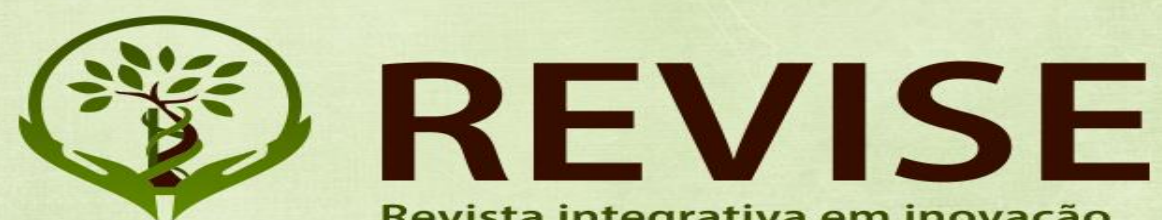

Revista integrativa em inovação tecnológica nas ciências da saúde

ISSN: 2179-6572

TABELA 1. Idade dos participantes do estudo

\begin{tabular}{|l|l|l|l|l|l|l|}
\hline Idade & $\mathbf{1 5 - 2 0}$ & $\mathbf{2 0 - 3 0}$ & $\mathbf{3 1 - 4 0}$ & $\mathbf{4 1 - 6 0}$ & $\mathbf{> 6 0}$ & $* * N I$ \\
\hline$* N^{\boldsymbol{o}}$ & 26 & 26 & 15 & 13 & 3 & 2 \\
\hline
\end{tabular}

Nota. (*) $\mathrm{N}^{\mathrm{o}}=$ Quantidade de respostas

$(* *) \mathrm{NI}=$ Não identificou.

Acredita-se que o baixo número de participantes com mais de 60 anos seja devido ao meio digital de aplicação do questionário que representa uma barreira tecnológica para as pessoas da referida faixa etária. Por outro lado, indivíduos da mesma faixa etária tende a ter um conhecimento tácito mais vasto a respeito das plantas para fins medicinais, passando esse conhecimento através das gerações (Pinto, Amorozo, \& Furlan, 2006). Dos 76 entrevistados que responderam já terem utilizado plantas medicinais, $81,6 \%$ adquiriu o conhecimento da finalidade terapêutica das plantas através da família; 7,9\% pela família e internet; $2,6 \%$ só pela internet; $1,3 \%$ por um profissional da saúde; $1,3 \%$ pela família e por um profissional da saúde; $1,3 \%$ pela família, internet e por um profissional da saúde; $1,3 \%$ por amigos; $1,3 \%$ pela família e por amigos; e 1,3\% por uma benzedeira. Totalizando 93,4\% adquiriram o conhecimento sobre os benefícios das plantas através da família, 11,8\% aprenderam na internet, e apenas 3,9\% por indicação de um profissional da saúde (Tabela 2).

Plantas medicinais. Revista Revise, vol 3, $n^{o}$ fluxo contínuo, p.46-60. 

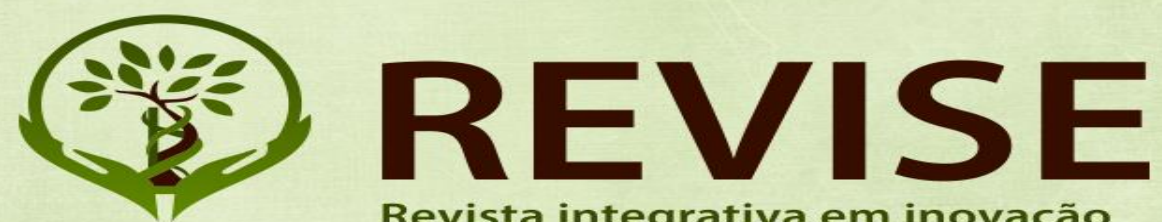

Revista integrativa em inovação tecnológica nas ciências da saúde

ISSN: $2179-6572$

TABELA 2. Fonte do conhecimento sobre a utilização das plantas medicinais

\begin{tabular}{ll}
\hline Modo & Número de pessoas \\
\hline Família & 71 \\
\hline Internet & 9 \\
\hline Profissionais da saúde & 3 \\
\hline Amigos & 2 \\
\hline Benzedeira & 1 \\
\hline
\end{tabular}

Em relação a localização, 31 pessoas são da cidade de Itamaraju e 22 de Teixeira de Freitas que foram os alvos da pesquisa. Apenas 3 pessoas são de Porto Seguro, 2 de Itabuna, e 1 indivíduo para as cidades de Divinópolis, Eunápolis, Itaju do Colônia, Manhuaçu, Medeiros Neto, Prado, Salvador, Ubaitaba, Ubatã e São Paulo. Houve 17 pessoas de origem não identificada. No total foram obtidas 72 espécies diferentes de plantas com uso medicinal. A erva cidreira (Melissa officinalis), foi a planta medicinal mais citada, com 40 indicações para diversas enfermidades, como dor de cabeça, ansiedade, estresse, indigestão, gases, cólicas intestinais, gripe, entre outros (Figura 1). Um estudo realizado na comunidade de Caiçara da Praia do Sono, no Rio de Janeiro, mostrou que a Melissa officinalis é muito utilizada no tratamento de enfermidades como pressão alta, cólica menstrual, calmante, vômito e diarreia (Brito \& Valle, 2011). Em seguida, o capim cidreira ou capim santo (Cymbopogon citratus) ocupou $2^{\circ}$ lugar com 30 indicações para tratar a ansiedade, gripe, febre, dor no estômago, dor de cabeça, insônia e outros. De acordo com Maia et al. (2011), a planta possui finalidade

Plantas medicinais. Revista Revise, vol 3, $n^{o}$ fluxo contínuo, p.46-60. 

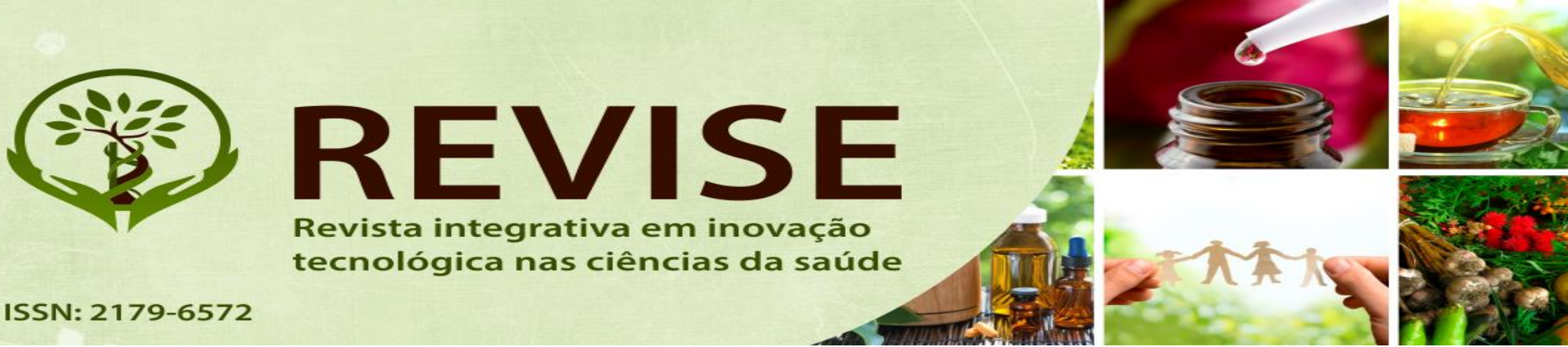

Revista integrativa em inovação tecnológica nas ciências da saúde

ISSN: $2179-6572$

terapêutica como, calmante, espasmolítica e analgésica, como também para tratamento de cólicas uterinas e intestinais, nervosismo, intranquilidade e ação antimicrobiana. Em $3^{\circ}$. lugar ficou o boldo (Plectranthus barbatus) com 29 indicações para problemas intestinais como: diarreia, intoxicação, azia, flatulência, cólicas abdominais. Já em Floriano no Piauí, o boldo foi a planta mais utilizada pela população para uma variedade de sintomas, que o estudo não especificou, sendo a folha a parte da planta mais utilizada pela população na preparação de chás (Vasconcelos, Alcoforado \& Lima, 2010). Logo após está a camomila (Matricaria chamomilla) com 22 citações para ansiedade, insônia, dor de cabeça, cólicas menstruais e gripe. Também foi demonstrado no estudo de Maia et al. (2011), que o uso da Camomila é eficiente contra cólicas, estimulante do apetite, sedativa e digestiva. Já outro estudo constatou que a planta é utilizada como calmante, para baixar a pressão e problemas nos rins, sendo a mata a principal fonte dessas espécies (Brito \& Valle, 2011) A erva doce (Pimpinella anisum), é indicada 14 vezes para males como dor de barriga, prisão de ventre, gases, ansiedade, febre e gripe. Estudos já evidenciaram que o óleo essencial extraído da Pimpinella anisum possui importantes finalidades terapêuticas para a reduzir os danos decorrentes do uso de morfina (Sahraei et al., 2002) e forte atividade antibacteriana (Gulçin et al. , 2003). A hortelã (Mentha sativa) e a babosa (Aloe vera) foram ambas citadas 11 vezes, sendo a hortelã indicada para enxaqueca, gripes e resfriados; e a babosa para cicatrização, tratamento de cabelo, gastrite, antiinflamatório e laxante. Um estudo realizado por Adjuto (2008), comprovou que a hortelã possui atividade antiparasitária, na eliminação de amebas e giárdias. Ainda de acordo com o estudo, chás com elevadas concentrações de hortelã possui efeitos similares a alguns remédios encontrados nas farmácias. De acordo com Coutinho et al. (2002) a Babosa possui ação antiparasitária, sendo a folha rica em aloína, de ação laxativa e vermífuga que age sobre protozoarios que parasitam o intestino humano (Atherton, 1997).

Plantas medicinais. Revista Revise, vol 3, $n^{o}$ fluxo contínuo, p.46-60. 

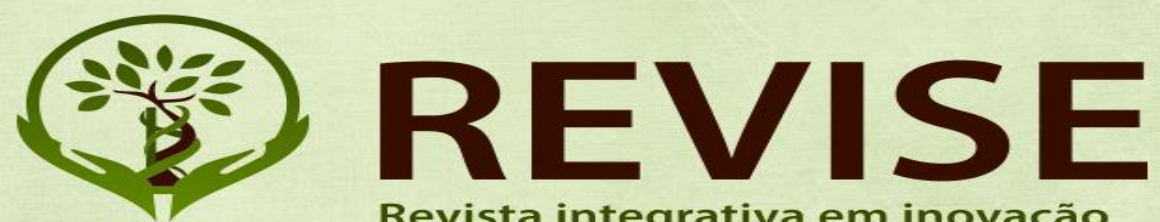

Revista integrativa em inovação tecnológica nas ciências da saúde

ISSN: $2179-6572$

FIGURA 1. Plantas medicinais mais usadas.

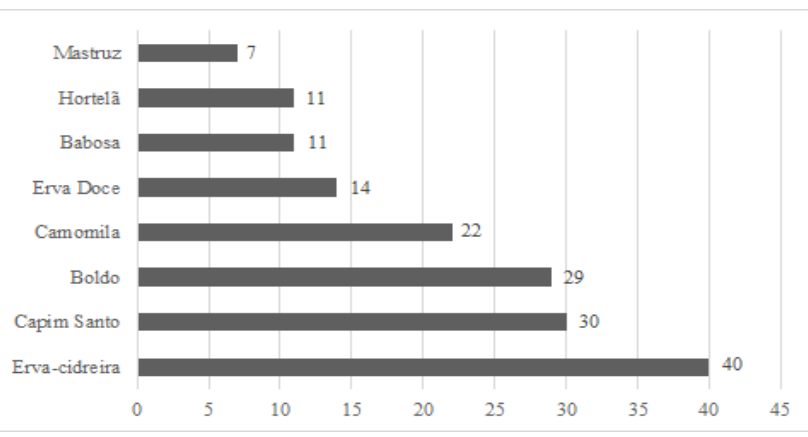

Como pode-se verificar na figura 2, a maioria do uso dessas plantas, são para enfermidades corriqueiras, como gripe, dores de cabeça, febre, problemas intestinais, como dor de barriga, gases, entre outros. Também pode-se notar que uma grande parcela das plantas é usada como calmante, para combater o estresse, ansiedade, e afecções muito frequentes no dia a dia, devido a intensa carga de trabalho, trânsito, e diversos outros fatores.

FIGURA 2. Indicações de uso plantas medicinais utilizadas para determinadas enfermidades.

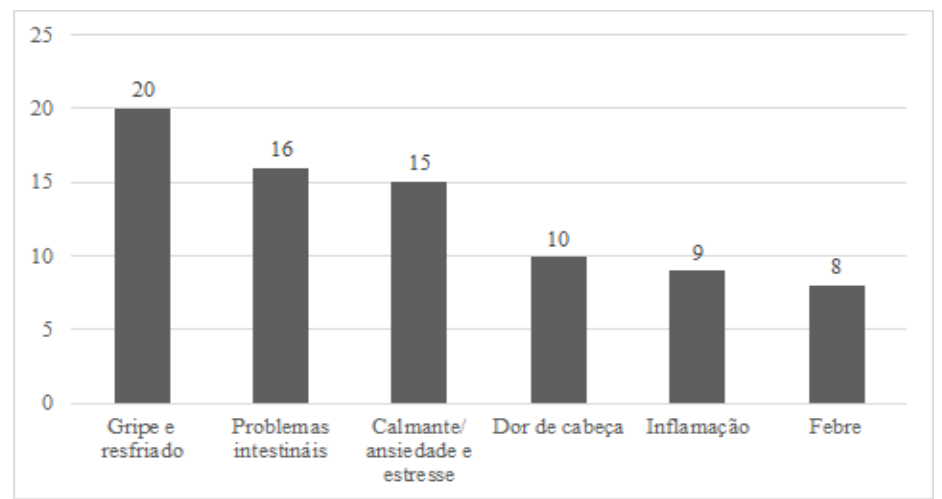

Plantas medicinais. Revista Revise, vol 3, $n^{o}$ fluxo contínuo, p.46-60. 

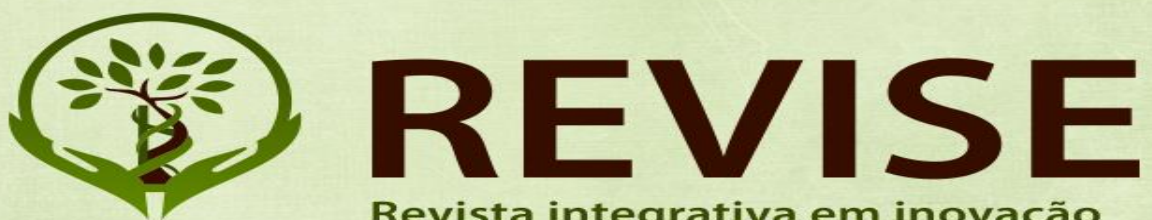

Revista integrativa em inovação tecnológica nas ciências da saúde

ISSN: $2179-6572$

Para o preparo dos remédios, as partes mais utilizadas foram as folhas (54 ou 63,52\%), seguida de caule ( 9 ou 10,50\%), flores ( 5 ou 5,88\%), raiz ( 4 ou $4,70 \%$ ), casca ( 4 ou $4,70 \%$ ), semente ( 3 ou 3,52\%), fruto ( 2 ou 2,35\%), seiva ( 2 ou 2,35\%) e houve também a utilização da planta inteira (2 ou 2,35\%) (Figura 3). O modo de preparo foi realizado 93\% por meio de chás, 9,7\% através de Sumo e 6,9\% de outras maneiras, como podemos ver na figura 4.

FIGURA 3. Partes das plantas mais utilizadas.

\begin{tabular}{|c|c|c|c|c|c|c|c|c|}
\hline \multirow{2}{*}{$\begin{array}{l}80,00 \% \\
60,00 \%\end{array}$} & \multicolumn{8}{|r|}{$63,52 \%$} \\
\hline & & & & & & & & \\
\hline \multicolumn{9}{|l|}{$40,00 \%$} \\
\hline $20,00 \%$ & $2,35 \%$ & $2,35 \%$ & $2,35 \%$ & $3,52 \%$ & $4,70 \%$ & $4,70 \%$ & $5,88 \% \quad 10,50 \%$ & \\
\hline \multirow[t]{2}{*}{$0,00 \%$} & - & - & - & - & - & - & - & \\
\hline & $\begin{array}{l}\text { Planta } \\
\text { inteira }\end{array}$ & Seiva & Fruto & Semente & Casca & Raiz & Flores & Folhas \\
\hline
\end{tabular}

FIGURA 4. Modos de preparo das plantas.

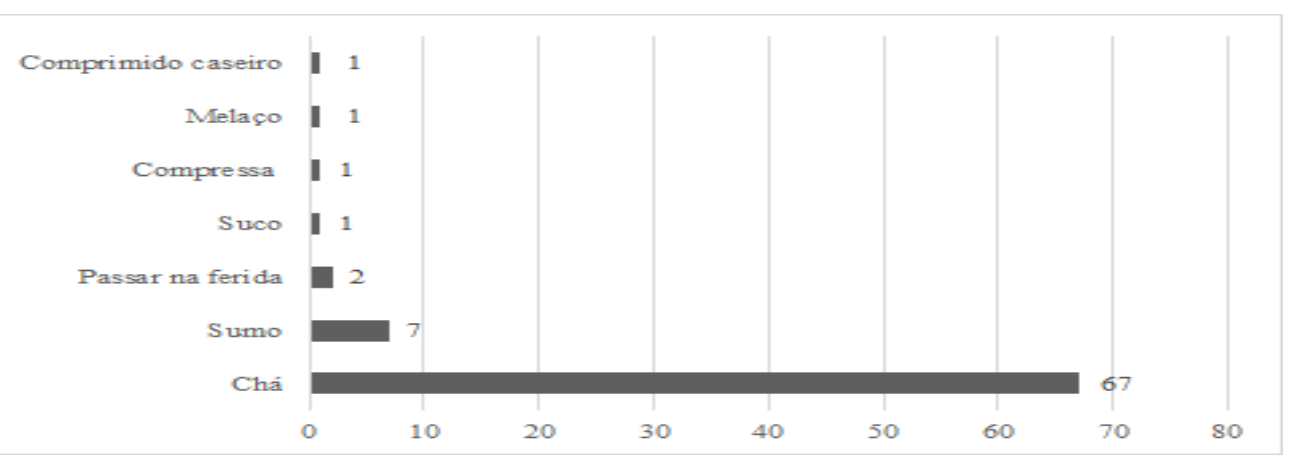

Também dentre os resultados, 3 pessoas $(3,52 \%)$ disseram que usam ou usaram a Maconha (Cannabis Sativa) para ansiedade, pressão alta e terapia. A Cannabis sativa, que entrou recentemente na lista das Denominações Comuns Brasileiras (DCB) da Anvisa, divulgada no dia 16 de maio de 2017, ainda não é reconhecida como planta medicinal no Brasil (Resolução

Plantas medicinais. Revista Revise, vol 3, no fluxo contínuo, p.46-60. 

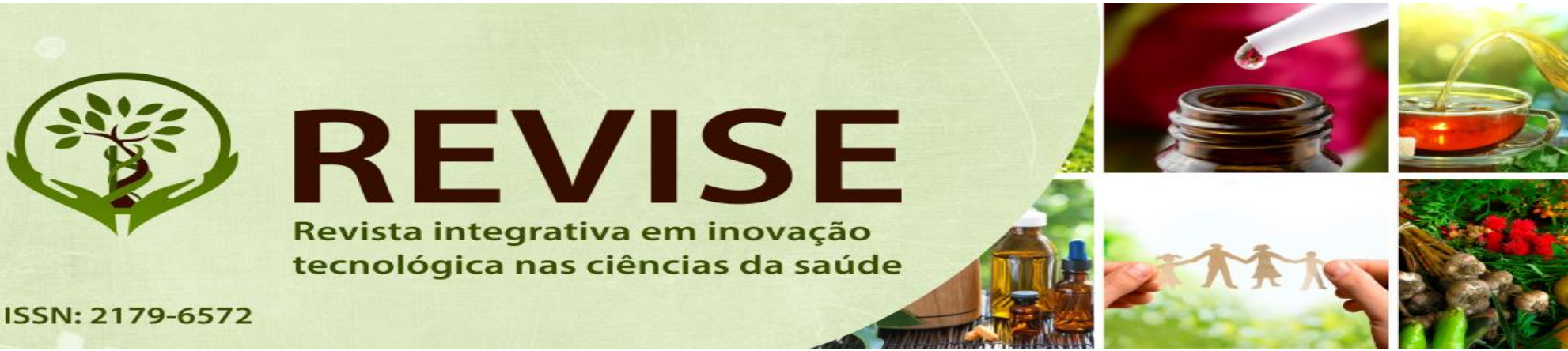

Revista integrativa em inovação tecnológica nas ciências da saúde

ISSN: $2179-6572$

da Diretoria Colegiada RDC n 156,2017$)$. Entretanto, essa denominação abre portas para que seja possível, depois da compilação de evidências clínicas, que a Cannabis sativa seja reconhecida oficialmente como tal, possibilitando até mesmo seu uso e importação como planta medicinal via registro legal junto a ANVISA ou por meio de decisões judiciais. Dos usuários das plantas medicinais, $96 \%$ disseram que os resultados foram eficazes, e somente $2,6 \%$ disseram não ter obtido sucesso terapêutico. Apenas 1 pessoa $(1,3 \%)$ alega não alcançar sucesso sempre, mas sim na maioria das vezes. Na utilização dos fitoterápicos, os efeitos colaterais identificados são poucos e geralmente ligados a vários fatores dentre eles a dosagem incorreta e/ou ao modo de preparo. Logo, o preparo correto é muito significativo para todo o processo, devendo-se estar atento a cada parte da planta usada, suas utilidades e aplicações (Arnoues et al., 2005). Alguns autores, como Veiga Junior et al. (2005), França et al. (2008) e Coan e Matias (2014), alertam para o cuidado com o uso indiscriminado das plantas sem as evidências científicas adequadas que, muitas vezes, estas são usadas para fins diferentes daqueles recomendados por estudos confiáveis. É errado pensar que por ser natural, não é tóxico e não faz mal à saúde. Existe uma variedade imensa de plantas medicinais que são providas de grande teor de toxicidade, portanto, é prudente procurar orientação adequada antes de consumir certas espécies. É essencial utilizar as plantas corretamente para que se possa usufruir de todos os seus benefícios, sem correr riscos. Com os devidos cuidados em sua aplicação, observamos, como apontado por França et al (2008), que a fitoterapia propicia uma reconexão do homem com a natureza em razão da saúde do organismo, normalizando suas funções fisiológicas prejudicadas e reestruturando a imunidade, para desintoxicar e rejuvenescer o sistema corporal.

Plantas medicinais. Revista Revise, vol 3, $n^{o}$ fluxo contínuo, p.46-60. 

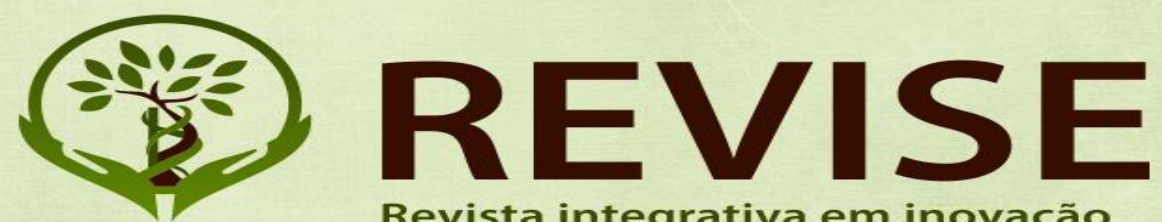

Revista integrativa em inovação tecnológica nas ciências da saúde

ISSN: $2179-6572$
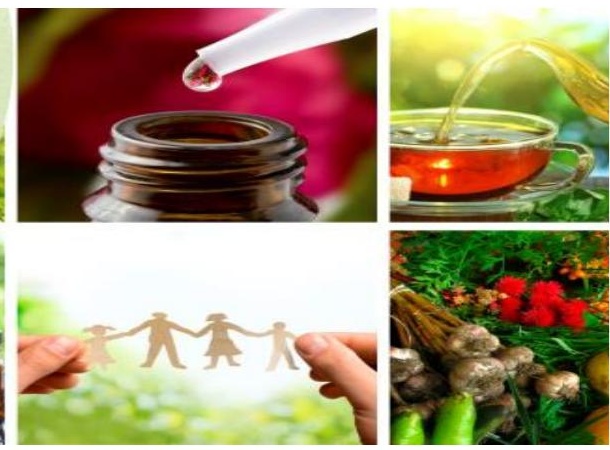

\section{CONCLUSÃO}

O conhecimento popular e a utilização das plantas medicinais permanecem amplamente preservadas pelas pessoas no extremo sul da Bahia. A sociedade deve buscar preservar e incentivar a prática da utilização de plantas medicinais e, em conjunto, estimular a pesquisa nesse campo. Considerando que o uso de plantas pode ser uma alternativa que pode proporcionar benefícios à saúde da população com acesso mais restrito às terapias com fármacos sintéticos tradicionais além de conscientizar as pessoas sobre o valor da preservação dos recursos terapêuticos naturais no meio ambiente, faz-se necessário, estimular um maior número de adeptos à prática com base em evidências clínicas e científicas. A capacitação e aperfeiçoamento de profissionais de saúde sobre os benefícios das plantas medicinais e suas formas adequadas de manejo podem ser alternativas racionais que respaldem a introdução responsável da fitoterapia a oferta de tratamentos nos serviços de saúde pública. Arnoues et al (2005), sugerem que é possível inserir os estudos e o conhecimento sobre as plantas medicinais nos cursos de saúde, encorajando novas ideias acerca das terapias tradicionais, e abrindo portas na relação entre o conhecimento tácito da população e o conhecimento acadêmico dos profissionais de saúde. Futuras avaliações fitoquímicas e farmacológicas são necessárias para contribuir com mais informações técnicas acerca dessas plantas, objetivando o melhor uso.

Plantas medicinais. Revista Revise, vol 3, no fluxo contínuo, p.46-60. 

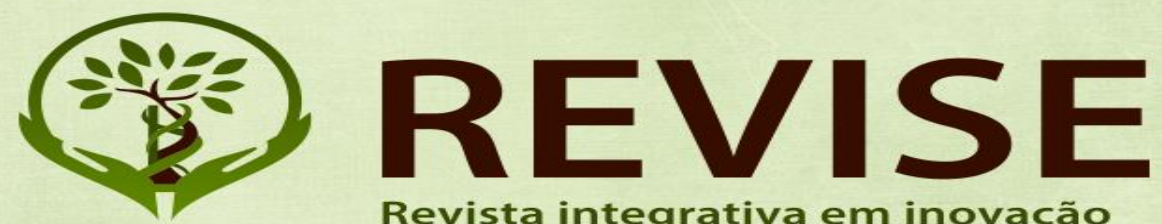

Revista integrativa em inovação tecnológica nas ciências da saúde

ISSN: 2179-6572

\section{REFERÊNCIAS}

ADJUTO, E. N. P. (2008). Caracterização morfológica e de óleo essencial de seis acesos de Hortelanzinho (Mentha spp.) (Dissertação de Mestrado). Faculdade de Agronomia e Medicina Veterinaria, Universidade de Brasilia, Brasilia, DF, Brasil.

ARNOUS, A. H., SANTOS, A. S., \& BEINNER, R. P. C. (2005). Plantas medicinais de uso caseiro - conhecimento popular e interesse por cultivo comunitário. Revista Espaço Para a Saúde, 6(2), 1-6.

ATHERTON, P. (1997). Aloe vera revisited. The British Journal of Phytotherapy, 4(4), 176183.

BADKE, M. R., BUDÓ, M. L. D., SILVA, F.M., \& RESSEL, L.B. (2011). Plantas medicinais: o saber sustentado na prática do cotidiano popular. Escola Anna Nery, 15(1), 132-139.

BRITO, M. R., \& VALLE, L. S. (2011). Plantas medicinais utilizadas na comunidade caiçara da Praia do Sono, Paraty, Rio de Janeiro, Brasil1. Acta Botânica Brasilica, 2(25), 363-372.

COAN, C. M., \& MATIAS, T. (2014). A utilização das plantas medicinais pela comunidade indígena de Ventarra Alta-RS. Sábios: Revista Saúde e Biologia, 9(1), 11-19.

COUTINHO, D. F. COUTINHO, D. F., TRAVASSOS, L. M. A., \& AMARAL, F. M. M. (2002). Estudo etnobotânico de plantas medicinais utilizadas em comunidades indígenas no estado do maranhão- Brasil. Visão Acadêmica, 3(1),7-12.

FRANÇA, I.S.X., SOUZA, J. A., BAPTISTA, R. S., \& BRITTO, V. R. S. (2008). Medicina popular: benefícios e malefícios das plantas medicinais. Revista Brasileira de Enfermagem, 61, (2), 201-208.

Plantas medicinais. Revista Revise, vol 3, no fluxo contínuo, p.46-60. 

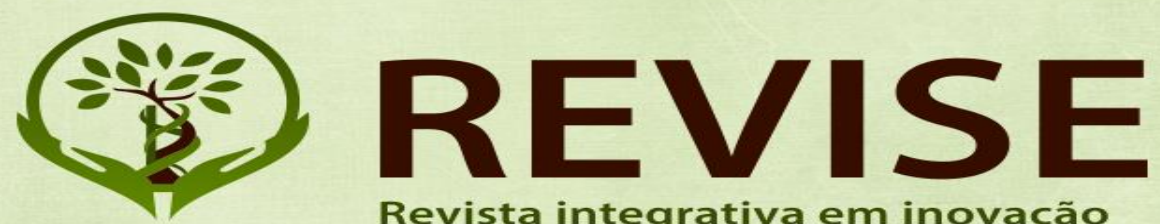

Revista integrativa em inovação tecnológica nas ciências da saúde

ISSN: 2179-6572

GÜLÇIN, I., OKTAY, M., \& KÜFREVIOGLU, O. I. (2003). Screening of antoxidant and antimicrobial activities of anise (Pimpinella anisum L.) seed extracts. Food Chemistry, 83(1), 371-382.

MAIA, E. A., FRANSCISCO J., PIRES, T., \& COIMBRA, S. M. (2011). O uso de espécies vegetais para fins medicinais por duas comunidades da Serra Catarinense, Santa Catarina, Brasil. Revista de Biologia e Ciência da Terra, 11(1), 54-74.

MINISTÉRIO DA SAÚDE. (2009). Programa Nacional de Plantas Medicinais e Fitoterápicos. Brasília: Autor. Recuperado de http://bvsms.saude.gov.br/bvs/publicacoes/programa_nacional_plantas_medicinais_fitotera picos.pdf

MOREIRA, R. C. T., COSTA, L. C. B., COSTA, R. C. S., \& ROCHA, E. A. (2002) . Abordagem Etnobotânica acerca do Uso de Plantas Medicinais na Vila Cachoeira, Ilhéus, Bahia, Brasil. Acta Farmacêutica Bonaerense, 21(3), 205-211.

PINTO, E. P. P., AMOROZO, M. C. M., \& FURLAN, A. (2006). Conhecimento popular sobre plantas medicinais em comunidades rurais de mata atlântica - Itacaré, BA, Brasil. Acta Farmacêutica Bonaerense, 4(20),751-762.

Resolução da diretoria colegiada $R D C n^{\circ} 156$, de 05 de maio de 2017. Alteração e exclusão de Denominações Comuns Brasileiras - DCB, na lista completa das DCB da Anvisa. Recuperado http://portal.anvisa.gov.br/documents/10181/2718376/RDC_156_2017_.pdf/8513f1a88f85-436a-a48c-1ae3e4c655b6b

SÁ, I. M. (2006). A interdisciplinaridade na pesquisa de plantas medicinais de uso tradicional. Revista de Ciências Agroveterinárias, 5(1),7-12.

SAHRAEI, H., GHOSHOONI, H., SALIMI, S. H., UM, A, M., SHAFAGHI, B., FALAHI, H., \& KAMALNEGAD, M. (2002). The effects of fruit essential oil of the Pimpinella anisum on acquisition and expression of morphine induced conditioned place preference in mice. Journal of Ethnopharmacology, 80(1), 43-47.

VASCONCELOS, D. A., AlCOFORADO, G. G., \& LIMA, M. M. O. (2010). Plantas medicinais de uso caseiro: conhecimento popular da região do centro do município de

Plantas medicinais. Revista Revise, vol 3, no fluxo contínuo, p.46-60. 

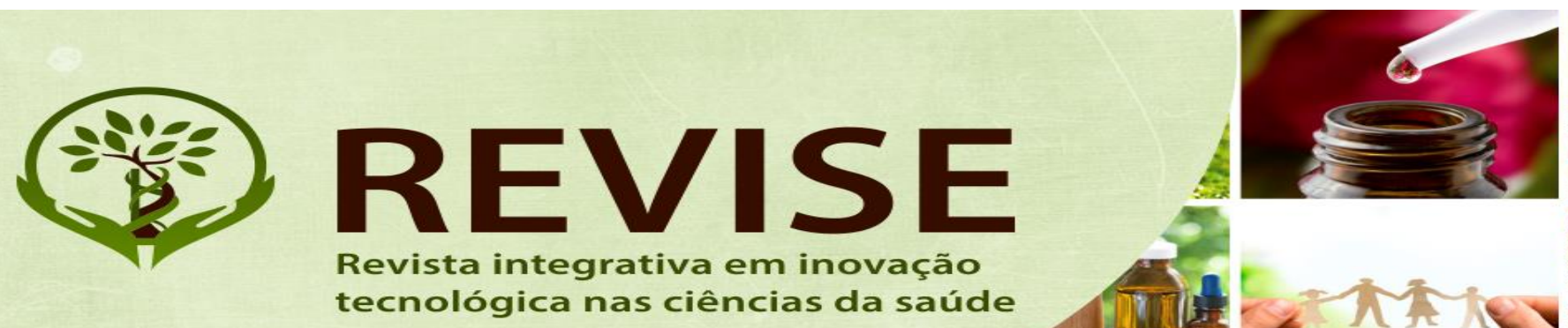

Revista integrativa em inovação tecnológica nas ciências da saúde

ISSN: $2179-6572$

Floriano/PI. Congresso de Pesquisa e Inovação da Rede Norte Nordeste de Educação Tecnológica, Maceió, Alagoas, Brasil, 5.

VEIGA JUNIOR, V. F., PINTO, A. C., \& MACIEL, M. A. M. (2005). Plantas medicinais: cura segura? Química Nova,28(3),519-528. 